\title{
breve panorama da trajetória do instituto nacional do mate: alguns apontamentos sobre erva-mate e economia nacional ${ }^{\star}$ brief overview of the trajectory the yerba mate national institute: some notes on the yerba mate and the national economy
}

\author{
José Antonio Fernandes $\star \star$ \\ Faculdade de Filosofia, Letras e Ciências Humanas, Universidade de São Paulo, São Paulo, Brasil
}

\section{RESUMO}

No presente texto, através de revisão bibliográfica e fontes primárias, desejamos tratar sobre o mercado ervateiro, inserindo-o nas lógicas econômicas nacional e internacional, no que diz respeito ao mercado interno e às exportações, focando especialmente em suas relações com a Argentina, principal comprador de erva-mate brasileira, mas também com o Chile e o Uruguai. Faremos algumas considerações sobre a busca por expansão de mercados, que inclui, sobretudo, a América do Norte e a Europa. Atentamos, por fim, de forma ensaística para a compreensão das estruturas e conjunturas políticas envolvendo as ações do Instituto Nacional do Mate (INM), as políticas econômicas nacionais e a busca pela industrialização do produto. Nesse sentido, a fim traçar um limite para este texto, convém-nos focar o estudo na produção e comércio do mate no período de vida do instituto (1938-1967).

Palavras-chave: Erva-mate. Economia ervateira. Economia brasileira. Instituto Nacional do Mate. Processo de industrialização.

\section{Abstract}

In the present text, through a bibliographical review and primary sources, we wish to deal with the Brazilian market, inserting it into the national and international economic logic, with regard to the domestic market and exports, focusing especially on its relations with Argentina, largest consumer of Brazilian yerba mate, but also with Chile and Uruguay. We will make some considerations about the quest for market expansion, which includes, above all, North America and Europe. Finally, an attempt made in the essay form to understand the structures and political conjunctures involving the actions of the yerba mate National Institute (Instituto Nacional do Mate - INM), national economic policies and the search for the industrialization of the product. In this sense, in order to draw a limit to this text, it is convenient to focus the study on the production and trade of yerba mate during the life of the INM (1938-1967).

Keywords: Yerba mate.Yerba mate economy. Brazilian economy. Instituto Nacional do Mate. Industrialization process.

* A pesquisa que originou este texto contou com o apoio da Coordenação de Aperfeiçoamento de Pessoal de Nível Superior (CAPES).

Submetido: 1ำ de fevereiro de 2017; aceito: 2 de janeiro de 2018.

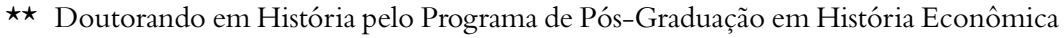
da Universidade de São Paulo. Mestre em História pela Universidade Federal da Grande Dourados. Professor da Rede Estadual de Santa Catarina.E-mail:jose_jaf@, hotmail.com 


\section{Introdução}

A erva-mate foi muito importante para a formação de quatro estados brasileiros (Paraná, Santa Catarina, Rio Grande do Sul e Mato Grosso ${ }^{1}$ ) e ela já teve uma parcela significativa nas exportações brasileiras, chegando a representar 3,7\% do valor das exportações nacionais em $1908^{2}$. Sendo produto de extração, ensaiou em alguns momentos o plantio, inclusive havendo alguns campos experimentais em Santa Catarina, no Paraná e no Rio Grande do Sul, mas não alcançou nada de tão representativo. Desde tempos coloniais usaram-se técnicas rudimentares, que sofreram mudanças e melhorias ao longo dos séculos, mas ainda assim conservaram algumas de suas características que, em meados do século $\mathrm{XX}$, autores envolvidos com o tema de sua cultura reconheciam ser atrasadas ${ }^{3}$.

Nessa produção dividiam-se as funções entre os que trabalhavam (indígenas, paraguaios e caboclos, dependendo do estado) e os que coordenavam (que poderia incluir o dono, arrendatário ou posseiro da terra ou não), depois os que intermediavam o comércio e finalmente os que exportavam (cf. Fernandes, 2017). Isso porque quase tudo que se produzia tinha como destino o mercado externo, que se resumia, sobretudo, à Argentina, ao Uruguai e ao Chile desde meados do século XIX.

Esses três países formavam os chamados mercados tradicionais da erva-mate brasileira e foram eles que fizeram nossa economia ervateira viver seus anos dourados, com o fortalecimento do parque moageiro do Paraná e de Santa Catarina, além do início da extração ervateira no antigo sul de Mato Grosso por Thomaz Laranjeira, no fim do século XIX, e do

1 Houve alguma exploração no oeste de São Paulo, na região fronteiriça com o Mato Grosso, mas isso se deu especialmente a partir da década de 1940, não representando muito em comparação com os demais estados, sendo quase irrisório diante de uma economia estadual que viveu durante muito tempo baseada na produção de café. A título de exemplo, dados mostram uma exportação de erva-mate do estado em 1944 na quantia de 24toneladas (Instituto Nacional do Mate, Relatório do presidente do Instituto Nacional do Mate, Carlos Gomes de Oliveira, apresentado à Junta Deliberativa, Rio de Janeiro, out. 1945, p. 100).

2 Anuário estatístico do Brasil, Rio de Janeiro: IBGE, ano V, 1939-1940, p. 1.379-1.380.

3 Exemplo dos "soques", tipos considerados inferiores (anti-higiênicos) de engenhos de mate, existentes em grande quantidade no Rio Grande do Sul, foram amplamente combatidos pelo INM, que buscava uniformização dos tipos industriais produzidos. 
empreendimento por ele iniciado que ficaria conhecido como Companhia Mate Laranjeira (cf. Fernandes, 2017). O Rio Grande do Sul teve o auge de sua exportação (em volume e valores) no século XIX, especialmente nas décadas de 1850 e 1860, com influência direta da Guerra do Paraguai (Rosa, 2015, p. 73-76), situação que foi se alterando até a década de 1930, quando passou a não fazer mais regularmente, concentrando-se, sobretudo, em seu mercado estadual, passando a absorver o que produzia e em diversos momentos comprando de outros estados (cf. Zarth, 1997; também Gerhardt, 2013).

Entre altos e baixos, a boa fase, sobretudo para os industriais, duraria até a década de 1930, a partir de quando a erva-mate passou a viver uma situação de crise não em termos de produção (pelo contrário, havendo superprodução), mas, sim, de preços e de mercados - especialmente com a Argentina, que passou a usufruir dos resultados dos ervais plantados em Missões. Isso pode ser percebido tendo em vista que depois dessa década se acentuou uma tendência à queda no valor das exportações que eram então pagas em libras: enquanto o valor médio pago pela tonelada fora de $\mathcal{E} 29,9$ na década de 1910 , na de 1930 se reduziu a $\mathcal{E}$ 12,2. A queda não foi tão significativa em termos de quantidade média exportada: 69.116 toneladas na década de 1910 contra 68.395 toneladas na década de $1930^{4}$.

É nesse contexto de crise que surgiu o Instituto Nacional do Mate (INM) ${ }^{5}$, em 1938, no início do Estado Novo de Getúlio Vargas, na fase de maior intervencionismo estatal na economia brasileira. Ele aparecia como uma resposta aos pedidos de industriais (beneficiadores) ervateiros por ação oficial, o que acabou gerando atritos com produtores de cancheada ${ }^{6}$ e com o nascente movimento cooperativo ervateiro.

Com as pesquisas que vimos desenvolvendo sobre o tema ${ }^{7}$, é possível até aqui identificar que havia, por parte do INM, uma busca pela

4 Anuário estatístico do Brasil, Rio de Janeiro: IBGE, ano V, 1939-1940, p. 1.375.

5 Os documentos do Instituto Nacional do Mate (atas, contratos, relatórios, legislação etc.) estão em grande quantidade digitalizados e disponíveis no Centro de Documentação Regional da Universidade Federal da Grande Dourados (UFGD).

6 Erva-mate semipreparada, antes de ser beneficiada, mas que já serve para o consumo em alguns formatos (chimarrão ou tereré, por exemplo), caracterizada, no entanto, como "matéria-prima" por alguns autores (Linhares, 1969) e presidentes do INM.

7 Referimo-nos a nossa pesquisa de doutorado em andamento no momento de produção deste texto. 
transformação da produção ervateira cada vez mais em produção industrial. Isso fica visível quando temos em mente os documentos do instituto. O que não agradava aos industriais brasileiros era a paulatina transformação da Argentina, principal comprador do nosso mate, em produtor e industrial também (pelo menos desde a década de 1930) - o que acabou alterando o tipo de erva-mate que seguia para lá, que de beneficiada (industrializada) foi passando a ser cancheada. E mesmo essa venda de cancheada para a Argentina só sobreviveu porque havia uma preferência pelas misturas com tipos de erva-mate brasileira produzidas no Paraná e, sobretudo, em Mato Grosso, o que, por sua vez, explicaria em parte a queda dos valores conseguidos com as exportações, já que os preços da cancheada eram bem menores que os pagos pela erva-mate beneficiada. Mas isso não é tudo, pois a Argentina já era autossuficiente no produto, podendo, por meio de propaganda ou adaptação de gostos, introduzir a sua produção nacional de cancheada; ainda assim continuou comprando a erva-mate brasileira, devendo somar-se a isso, então, também questões diplomáticas, tendo a ver com a compra de trigo argentino por parte do Brasil - produto que foi incluído nas negociações dos Tratados Comerciais Brasil-Argentina de 1933, 1935 e 1953 (Reckziegel, 2005, entre outras, p. 4-6; podem ser encontradas informações também nos relatórios dos presidentes do INM, especialmente a partir de 1952).

Já o Uruguai e o Chile continuaram comprando erva-mate industrializada durante todo o tempo de vida do INM (1938-1967) (cf. Costa, 1995) - embora no caso uruguaio tenha havido certo processo de industrialização interna também, criando lá, a partir da década de 1940, um mercado para cancheadas brasileira, argentina e também paraguaia ${ }^{8}$.

Em todo caso, pode-se perceber, através da documentação do instituto, que mudanças foram ocorrendo nos domínios da produção em todos os estados ervateiros do Brasil, com uma inversão paulatina nos tipos exportados, que era dominantemente de erva-mate beneficiada e que passou a sofrer cada vez mais com a concorrência da cancheada. Mostra disso é que no Paraná, principal estado produtor, a exportação

8 Sobre isso há uma ampla discussão nos relatórios de presidentes do INM, inclusive nas atas da Junta Deliberativa e da Diretoria, em que aparecem menções às negociações para limitar essa industrialização uruguaia. 
de mate beneficiado vinha cedendo lugar, já desde o fim do século XIX, ao mate cancheado desse estado e também ao mate cancheado do antigo sul de Mato Grosso, que foram ganhando espaço e importância a partir de então (Fernandes, 2017).

\section{Industrialização do mate: experimentos e reformulações do tradicional}

O INM tentou desenvolver a industrialização ervateira brasileira, criando tipos e subtipos, promovendo pesquisas e o uso de extratos da planta, criando padronizações e produtos a serem inseridos nos "mercados velhos" e nos novos a serem conquistados. Nesse sentido, pensemos em alguns formatos em que a erva-mate era conhecida e como foi apresentada ao público, especialmente aos novos mercados.

Sendo assim, podemos dizer que a erva-mate é lembrada frequentemente em sua forma mais tradicional: o chimarrão. Trata-se de um tipo de mate quente consumido por meio de uma cuia e uma bombilha. Mas nos estados mais quentes do Brasil, como o antigo sul de Mato Grosso (hoje Mato Grosso do Sul), ela foi adotada pelos índios e depois pelos não índios (que aprenderam com os índios) no formato tereré, tipo de mate gelado tomado com equipamentos semelhantes aos do chimarrão, mas aceitando tipos menos elaborados e com peneiração mais grossa.

Nesse cenário de industrialização, o tipo solúvel ocupou o instituto por vários anos e continuou aparecendo, após o fim de suas atividades, em relatório do Instituto Brasileiro de Desenvolvimento Florestal (1975). O mate solúvel, subproduto concentrado destinado a ser consumido como chá, foi muito considerado na esperança de ampliação dos mercados, sobretudo pela resistência que havia ao consumo do mate em formato chimarrão, na Europa e nos Estados Unidos. De mate solúvel existiram, ao longo do século XX, fábricas nos quatro principais estados produtores de erva-mate (Paraná, Santa Catarina, Rio Grande do Sul e Mato Grosso).

Exemplo disso é a Matex, fábrica instalada em 1961, em Ponta Porã, sul de Mato Grosso, pela Federação das Cooperativas de Mate Amambai (COPEMA), com estudos da firma Equiplan, tendo sido imaginada e construída pela firma suíça Luwa do Brasil. Na Matex foram investidas 
altas quantias de capital (Cr\$200 milhões ${ }^{9}$ ), tendo capacidade para oferecer ao mercado grande quantidade do subproduto, operando com três conjuntos de geradores e uma caldeira a vapor, e possuindo ainda um silo elevado com capacidade para 750 sacos de 60 quilos e processo de armazenamento mecanizado, "com a erva sôlta circulando por conduto controlado da base", o que inicialmente a programava para ter capacidade de 1.200 quilos diários de produto pronto. Para sua manutenção, possuía esquema de contribuição das cooperativas filiadas (com 10\% de sua produção) (Figueiredo, 1967, p. 371). Havia inclusive uma ideia, por parte da Federação, de fabricar refrigerante engarrafado, a fim de "competir com os refrigerantes atuais" (Figueiredo, 1967, p. 373). Apesar dessas condições e fazendo uso de propaganda intensa, começando a fabricar mate solúvel em 1962, a partir do tipo cancheado MB1, o empreendimento acabou não dando o retorno esperado; devido à falta de mercado até 1967, ano do texto de Figueiredo e quando o INM é extinto, a Matex estava trabalhando anualmente apenas uns três meses ao ano, acarretando inúmeros problemas, "como o da renovação constante de mão-de-obra” e o acúmulo de estoques (1967, p. 372).

Mas a erva-mate foi também, ao longo da existência do INM e depois dele, objeto de outros experimentos e usos diversos. Alguns empresários já vinham tentando a fabricação de mate em forma de refrigerante gaseificado na década de 1950. A título de exemplo, esse é o caso da Cervejaria Corumbaense, de Corumbá, antigo sul de Mato Grosso, que fabricava um refrigerante à base de mate denominado "Mate Chimarrão"10, que, segundo dizia o instituto, era "o que de melhor se conseguiu fazer até hoje [1956], no gênero, não só pelo seu agradável sabor, como pela sua magnífica apresentação"11.

No mesmo sentido, surgiu e se fixou o chá tostado ou mate queimado - nesse caso, este é comercializado até os dias atuais (2017), entre outras, com a marca Matte Leão. Esses tipos ganharam ao longo dos anos suas versões misturadas, como o mate com leite, que pode ser consumido

\footnotetext{
9 Recurso que foi "arrecadado com as sobras das altas dos preços em virtude da elevação do dólar (uso de retôrno)", e os sócios da COPEMA destinavam tal retorno à construção da fábrica (Figueiredo, 1967, p. 371).

10 O nome foi contestado pelo INM, pois não tinha nada a ver com o tipo chimarrão a que nos referimos nos parágrafos anteriores deste texto.

11 Instituto Nacional do Mate, Ata da $22^{a}$ sessão ordinária da Diretoria, 27 de fevereiro de 1956.
} 
em alguns lugares, como nas franquias Casa do Pão de Queijo ou Rei do Mate, por exemplo. Dessas misturas também se acha com canela, pêssego, limão, entre outras. Em termos amplos, ao lado do chimarrão consumido principalmente no Rio Grande do Sul, o chá tostado é hoje o tipo mais popular de consumo de erva-mate.

Ainda sobre o chá tostado, há décadas os tipos gelados podem ser consumidos nas praias do Rio de Janeiro (e em outras), em quiosques, e comprados de vendedores ambulantes, como podemos encontrar em diversos documentos sobre a erva-mate. Daí surgindo ainda bebidas de mate, como uma marca recente (2017) do grupo Viton 44, chamada Matte Viton - que patrocina times e atletas cariocas.

Além dos produtos propriamente, existem as substâncias extraídas do mate, como a "mateína" (uma espécie de cafeína), que há tempos vem sendo cobiçada por algumas grandes companhias, como a Coca-Cola, que por sinal comprou a marca Matte Leão. Generoso Ponce Filho, presidente do INM, citou, no relatório de março de 1947, indústrias que extraíam substâncias químicas do mate, como a referida mateína, a clorofila, a teobromina, a vitamina K, o carvão ativo, entre outras ${ }^{12}$. E hoje em dia temos também empresas que usam erva-mate para fabricar cosméticos (shampoos, cremes etc.), xaropes para fins farmacêuticos e bebidas alcoólicas (artesanais ou não), como licores de erva-mate. Especificamente sobre cosméticos, um exemplo é o da empresa Natura, com os produtos da série Ekos, que incluem sabonete, colônia, shampoo e creme de barbear à base de mate.

Por último, é interessante dizer que, ao longo dos séculos XIX e XX, muitos estudos foram feitos, incluídos em ações de propaganda, em que se buscava mostrar que o mate tem propriedades medicinais ou no mínimo ações ativas no organismo, servindo, por exemplo, como diurético e organizador da flora intestinal. Aliás, em relação à Alemanha (na unificada e na Ocidental depois da Segunda Guerra), um dos novos mercados que eram pretendidos pelo INM, o mate era conhecido mais como botica do que como sobremesa, vendido em Reformhäuser (lojas de produtos dietéticos) $)^{13}$.

12 Instituto Nacional do Mate, Relatório do presidente do Instituto Nacional do Mate, Generoso Ponce Filho, apresentado à Junta Deliberativa, Rio de Janeiro, mar. 1947, p. 15.

13 Instituto Nacional do Mate, 32a sessão ordinária da Diretoria, 28 de junho de 1962. 


\section{A economia brasileira e o INM}

Como vimos, o INM surgiu com Getúlio Vargas e o Estado Novo, em 1938, e teve suas atividades encerradas em 1967, em pleno Regime Militar. O Brasil em 1938 já havia iniciado um processo de transformações profundas em sua economia, motivadas pela Primeira Guerra Mundial, mas depois, sobretudo, pela crise mundial iniciada em 1929 e pela Revolução de 1930 em nosso país. Tivemos então o momento de "substituição de importações", em que ocorreu um crescimento do parque industrial e uma intensa ação do Estado nesse sentido (Cohn, 1978, p. 296). Além disso, após a Primeira Guerra, temos o momento de emergência dos Estados Unidos "como centro econômico dominante na constelação da qual faz parte o Brasil, tanto no que concerne ao volume de investimentos feitos no país, quanto na área das trocas internacionais" (Cohn, 1978, p. 297-298). Claro que o país não se alinhará de imediato aos norte-americanos, quando, mesmo com as crescentes tensões mundiais da década de 1930, mantinha uma postura neutra (equidistante), havendo espaço para acordos comerciais também com a Alemanha nazista, só se definindo a partir da década de 1940,já com o acirramento dos conflitos bélicos da Segunda Guerra (cf. Moura, 1980).

Até o ano de 1967, vemos um longo caminho pelo qual a economia brasileira percorreu com seus altos e baixos. Ocorreram notáveis avanços na industrialização nacional, não sem sacrifícios, com inversões de capital estrangeiro em menor ou maior intensidade de acordo com os governos que se sucederam; período em que, apesar das conquistas trabalhistas, contou com grandes desníveis em termos sociais e econômicos, que afetaram a qualidade de vida e o poder de consumo da população assalariada, sem qualquer outra forma de remuneração, seja da cidade ou do campo.

Tomemos os pontos acima referidos, a fim de analisarmos de que forma todo esse trajeto da economia brasileira também afetou a economia ervateira e é isso que precisamos focar nas próximas linhas, ainda que, valendo o lembrete, muita coisa ainda esteja em processo de pesquisa e não pretendamos aqui uma análise profunda e definitiva de cada um deles.

Entendemos então que industrialização seja um processo,

um conjunto de mudanças, dotado de uma certa continuidade e de um 
sentido. Se sentido é dado pela transformação global de um sistema econômico-social de base não industrial (no caso brasileiro: de base agrária-exportadora). (Cohn, 1978, p. 283)

Embora não entendamos esse "sentido" (que poderíamos chamar de formação, evolução ou coisa que o valha) de forma linear, havendo também retrocessos, resultado de políticas ineficazes e mesmo reacionárias dos governos brasileiros. Sendo assim, em relação à industrialização brasileira e seus sacrificios, temos em mente que a economia nacional passou por um momento de intenso intervencionismo e centralização, durante os governos deVargas (1930-1945,1951-1954) e especialmente durante o Estado Novo (1937-1945). Centralização que tem como alguns de seus pontos marcantes a reforma do Ministério da Agricultura e a criação do Ministério do Trabalho, Indústria e Comércio (ao qual o INM era subordinado antes de passar ao Ministério da Agricultura), mostrando uma preocupação intensa com a racionalização no nível administrativo, além dos órgãos criados "para dar maior amplitude e flexibilidade à ação oficial”, entendendo que os esforços que

teriam grande incremento no período posterior a 1937, implicavam em reforçar a instituição de uma economia capitalista diferenciada no país, e, por essa via, as suas bases de execução e de sustentação políticas seriam recrutadas cada vez mais nitidamente nos centros urbanos. (Cohn, 1978, p. 299)

Ao menos de forma aparente, houve por parte das pessoas que estiveram ligadas à fundação do INM um ideal de nacionalismo, de sacrificio “em prol da Nação”. É assim que na sessão de instalação do instituto, em 20 de julho de 1938, seu presidente Diniz Júnior disse que este iria "constituir o primeiro ente autárquico do Estado Novo"; "o primeiro órgão creado sob os moldes corporativos", como diria na mesma reunião ArturTorres Filho, membro do Conselho Federal de Comércio Exterior, agora representante dos produtores de Santa Catarina, completando que esperava que o INM harmonizasse "as classes e os interesses, para que o Brasil se beneficie e consiga fazer da indústria ervateira um dos esteios da expansão, da riqueza, da cultura do Brasil’" ${ }^{\prime 4}$. Significativa foi a manifestação

14 Instituto Nacional do Mate, Ata da sessão de instalação do INM, 20 de julho de 1938, p. 1,4 , grifo nosso. 
nessa mesma reunião feita por Generoso Ponce Filho, à época delegado do governo de Mato Grosso, que disse que, a princípio, combateu a criação do INM,

porque os problemas dos produtores [de cancheada de seu estado] não estavam de acordo com ele. Parecia que a situação dos produtores matogrossenses dentro do órgão a ser creado, viria a ser, tão sómente, a de contribuintes imediatos, sem que, por maior amplitude que o Instituto imprimisse a propaganda no exterior, Mato Grosso auferisse benefícios, uma vez que era tão somente produtor de cancheada, que por sua natureza, não carece de ser objeto de propaganda para sua colocação no exterior. Portanto, creado que foi, pelo Governo da Republica, o Instituto Nacional do Mate, tendo tido a honra de ser convidado, pelo senhor Interventor de Mato Grosso [Júlio Müller], relutei a princípio, em aceitar a honrosa incumbência. Aceitei-a, entretanto, porque S. Excia. colocou a questão no seguinte pé: $O$ Instituto hoje é lei; temos de obedece-la ${ }^{15}$.

Ponce Filho parece demonstrar uma atitude passiva diante das políticas federais. Seria essa uma posição assumida por Mato Grosso diante do Estado Novo e da existência do INM? Disse ele ainda que "creou-se para defesa do produto brasileiro.Vamos, portanto, para o Instituto com grande espírito de brasilidade, confiantes na justiça dos nossos companheiros, na justiça dos órgãos públicos do Brasil", sendo-lhe prometido que "os interesses, peculiares, próprios, de cada uma das regiões brasileiras, não serão descurados", completando que "nós teremos, naturalmente, que trazer cada um a nossa quota de sacrificio, em beneficio comum do Brasil" 16 .

Muito significativo é ver, ainda, que o presidente Diniz Júnior, mesmo afirmando a necessidade de superar as diferenças entre os estados ervateiros, defendeu a industrialização:

O ideal seria atingirmos todos ao estagio industrial, a fase de transformação, do beneficiamento, visto que país de matéria prima vive ainda de subordinação, existência colonial, fonte de apetites dos mais fortes, dos que alcançaram,

15 Instituto Nacional do Mate, Ata da sessão de instalação do INM, 20 de julho de 1938, p. 5-6, grifo nosso.

16 Instituto Nacional do Mate, Ata da sessão de instalação do INM, 20 de julho de 1938, p. 6. 
com a industrialização, a independência, a civilização ao equilíbrio e prestígio de suas forças creadoras ${ }^{17}$.

Podemos perceber aqui a visão do presidente do INM como parte das políticas nacionalistas de desenvolvimento industrial do período Vargas; da substituição das exportações de produtos primários (como consideraria Diniz Júnior o mate cancheado) pelo desenvolvimento de uma indústria nacional.

Já na década de 1940, especialmente no governo Dutra, quando a discussão era liberalismo versus controle estatal, o INM dava suas amostras, em situações, discussões e posições que seguiriam nas décadas seguintes, ao longo do seu tempo de existência, no que diz respeito, sobretudo, ao regime de preços ou de cotas de exportação. As cotas de exportação (em termos de quantidade e divisão entre os interessados) alternaram com um regime de livre-comércio do mate durante alguns momentos ${ }^{18}$, assim como o regime de preços fixos foi sustado (ou mesmo burlado por intermediários em suas relações com os produtores) em diversos momentos. Mas, para além da questão de preços fixados e das cotas, de maneira geral, há aspectos contraditórios nas posturas assumidas e com frequência o que se vê é a defesa de uma ação efetiva do instituto, com reclames da falta de poder e ação ou mesmo da perda de controle, como quando da questão envolvendo o movimento cooperativista, em que fez a Junta Deliberativa do INM o impossível para conseguir para si os poderes que usufruía a Comissão de Organização Cooperativa dos Produtores de Mate $(\mathrm{COCPM})^{19}$, arguindo em sua defesa, em outubro de 1945, que

17 Instituto Nacional do Mate, Ata da sessão de instalação do INM, 20 de julho de 1938, p. 8 , grifo nosso.

18 Em relação às cotas, após viagem de Gil Stein Ferreira, em inícios de 1947, representando o Ministério da Agricultura, pelos estados produtores do Rio Grande do Sul, do Paraná e de Santa Catarina, saiu ele com a impressão, que transmitiu ao ministro, da necessidade de acabar com o regime de cotas, dizendo o presidente do INM que se tratava de "opinião que se generalizára e era, já então, apoiada pelos industriais e pelas Cooperativas"; propôs então Gil Stein à Junta Deliberativa do instituto a abolição do regime de cotas e a liberação da produção, do comércio, da indústria e da exportação, o que foi aprovado nas reuniões de mar. 1947 (Instituto Nacional do Mate, Relatório do presidente do Instituto Nacional do Mate, Generoso Ponce Filho, apresentado à Junta Deliberativa, Rio de Janeiro, out. 1948, p. 17).

19 Entre outros, contribuição de Cr\$ 1 por 15 quilos de erva-mate produzida no país, controle das vendas e fornecimentos por parte dos produtores cooperados, poder de negociar "qualquer operação de crédito sob a garantia de renda dessa contribuição". 
esta exercia "funções idênticas às do Instituto" e sendo os membros do INM "legítimos representantes de todas as classes" 20 - questão, aliás, que o instituto ganhou, tendo sido encerradas as atividades da comissão no ano seguinte.

Um exemplo da posição contraditória assumida pelos dirigentes ervateiros é que anos mais tarde o então presidente do INM, Generoso Ponce Filho, defendendo a liberdade, mostrava uma atitude na realidade bem intervencionista, ao defender também o planejamento, em que dizia caber ao instituto disciplinar os mercados externos, padronizar os tipos de erva-mate a serem vendidos, proibir a exportação de tipos inferiores, estabelecer cotas e fixar preços, pois a direção que seguia a economia

é, evidentemente, cada vez mais, no sentido da organização e do planejamento, e não no da liberdade sem peias, que teve sua época e sua utilidade, para o progresso das nações quando êste não havia atingido a escala astronômica de nossos dias e menos ainda quando as catastróficas consequências do segundo cataclisma, deixaram o mundo abalado em seus próprios alicerces, como numa grande convulsão telúrica ${ }^{21}$.

Em resumo, demonstra certa obviedade, afinal, foi com a finalidade de controlar que o instituto foi criado. Só que havia outra limitação, importante por sinal, que apareceu em diversos momentos nas reclamações dos presidentes: o fato de o INM não poder agir como comerciante.

Mas, ampliando novamente o campo de visão, veremos que, se a partir de 1930 o Estado nacional intervinha e assumia um caráter marcadamente nacionalista, a partir do segundo governo Vargas ocorre uma abertura maior ao capital externo, estando em jogo naquele momento duas concepções opostas sobre a industrialização e utilização de recursos do país, uma nacionalista e outra liberal,

uma reconhecendo, como é justo, a situação peculiar e toda especial da economia e das finanças do Brasil que exigem, por sua debilidade congê-

20 Instituto Nacional do Mate, Relatório do presidente do Instituto Nacional do Mate, Carlos Gomes de Oliveira, apresentado à Junta Deliberativa, Rio de Janeiro, out. 1945, p. 5-8.

21 Instituto Nacional do Mate, Relatório do presidente do Instituto Nacional do Mate, Generoso Ponce Filho, apresentado à Junta Deliberativa, Rio de Janeiro, mar. 1948, p. 5-8. 
nita e falta de reservas ponderáveis, uma regulamentação rigorosa da utilização dos parcos e de todo insuficientes recursos em divisas com que o país conta, a fim de lhes dar a mais proveitosa aplicação com vistas ao interesse geral e à conveniente estruturação da economia nacional. Em oposição a isso, encontra-se a concepção liberal, inspirada por um pensamento econômico sem nenhuma justificação no Brasil e amparada pelos interesses tanto nacionais como estrangeiros direta ou indiretamente ligados à tradicional ordem econômica dominante no país, e que julga preferível confiar na livre iniciativa privada, deixando a seu cargo, na base do livre jogo do mercado e da oscilação de preços daí derivada, a seleção das importações e a utilização das divisas disponíveis. (Prado Jr., 2004, p. 312)

O que se viu foi a vitória da segunda concepção, com a parcial liberação do câmbio através da Lei n. 1.807, de 7 de janeiro de 1953; regime que foi parcialmente modificado com a Instrução n. 70 da SUMOC, de outubro de 1953, por força da qual passaram a se realizar pela taxa oficial todas as exportações e importações, "ficando confinado o mercado de taxas livres às transações de caráter meramente financeiro - em particular a entrada e saída de capitais, bem como as remessas de juros, dividendos e outras formas de remuneração dos capitais estrangeiros" (Prado Jr., 2004, p. 310). O que constava na Instrução n. 70 foi confirmado depois pela Lei n. 2.145, de 25 de dezembro de 1953, e "se manteve em suas linhas gerais e essenciais até 1961, quando é restabelecida, praticamente em sua integridade, a liberdade cambial" (Prado Jr., 2004, p. 311). Esse novo sistema introduzido pela Instrução n. 70 "representava mais um passo no sentido do retorno à plena liberdade comercial e cambial, em substituição ao controle introduzido [...], em 1948, pelo sistema de licença prévia para importações" (Prado Jr., 2004, p. 311).

E, nesse mesmo panorama geral, vemos que nos demais governos o nacionalismo, representado pela defesa da industrialização nacional e de restrições à entrada e saída de capital estrangeiro, de um lado, e os defensores do liberalismo e das velhas formas em que se baseava a economia brasileira, na condição de país agrário-exportador de outro, também estiveram em pauta (veja-se a polêmica entre Eugênio Gudin e Roberto Simonsen em IPEA, 2010). Em menor ou maior intensidade, podemos observar esses debates e as medidas resultantes, com o pêndulo indo de um e de outro lado, no governo Dutra (1946-1951), nos governos pro- 
visórios pós-suicídio de Vargas, seguindo-se uma forte abertura aos investimentos externos (e drenagem de recursos deles resultantes) a partir de Juscelino (1956-1961), Jânio (1961), voltando (ao menos enquanto durou) a um centralismo relativamente mais intenso, embora frágil, com João Goulart (1961-1964).

Tomando o período Kubitschek (1956-1961), podemos ver um investimento maciço no desenvolvimento industrial, sobretudo as indústrias de base, no que foi incluído no Plano de Metas. Ao mesmo tempo, a agricultura recebeu bem menos atenção - não houve uma política de modernização das atividades desenvolvidas no campo. E nesse último caso podemos incluir a cultura extrativa e seu beneficiamento, como são as atividades ervateiras.

Somado aos governos de Jânio Quadros e mesmo parte do governo de João Goulart (ao menos até 1962), esse foi “o período áureo das inversões estrangeiras estimuladas pelos excepcionais favores e vantagens que lhes são proporcionados" (Prado Jr., 2004, p. 316). Inversões de capital que na economia brasileira, de maneira geral, se dividiram entre recursos nacionais e estrangeiros durante todo o período abordado neste artigo. Especificamente em relação à erva-mate e ao INM, os investimentos feitos se restringiram aos nacionais, tendo havido uma busca constante por financiamento das safras e para a promoção da industrialização do produto, mas com muita frequência os pedidos esbarraram nas negações por parte dos órgãos financiadores (como Banco do Brasil e Caixa de Crédito Cooperativo, por exemplo), ou nos financiamentos abaixo do solicitado ${ }^{22}$. Portanto, devemos considerar antes o que não ocorreu, ou seja, podemos dizer que as inversões estrangeiras não afetaram a produção ervateira e esta sempre padeceu da falta de financiamentos e empréstimos nacionais que realmente fizessem alguma diferença.

A partir de 1964, os militares, instalando-se no poder, passaram a cooperar diretamente com os norte-americanos e abriram espaço no Brasil para uma economia liberalizante, embora, no tratamento com as massas e dissonâncias, o regime fosse de exceção. Ou, como dizia Furtado, "liberal na substância e autoritário na forma", em que

22 Sobre isso ver, por exemplo, Oliveira (1974). 
pretendia-se "desestatizar" a economia, voltar aos estímulos indiretos, controlar a inflação com instrumentos monetários, restabelecer um "clima atrativo" para o capital estrangeiro, impor uma disciplina rígida à classe assalariada, enfim tudo que era costume apresentar como normas de bom comportamento para um país latino-americano antes de 1929. (Furtado, 1968, p. 18)

Embora não pudesse prever todos os passos que trilhariam os militares, com o "milagre" e o seu período posterior, Furtado via, ao menos até o ano em que esteve envolvido na organização de dados para escrever o livro Brasil: tempos modernos (1968), algumas mudanças de rumo, alguns desacertos e algumas inaplicabilidades do modelo puramente liberal da economia brasileira, chegando a dizer que a "doutrina liberal foi sendo arquivada", prevalecendo então "soluções oportunistas", com resultados que teriam que ser caóticos (Furtado, 1968, p. 21). Se ele errou em parte, o certo é que, nesse cenário pós-golpe, o INM não sobreviveu por muito tempo.

\section{O mercado brasileiro da erva-mate}

Devemos agora tomar especificamente a questão do mercado interno brasileiro da erva-mate ${ }^{23}$. A análise é complicada, se tomarmos a qualidade dos dados disponíveis, mas faz-se necessário um trabalho sistemático e amplo, havendo neste texto apenas algumas considerações a respeito ${ }^{24}$.

Em relação ao consumo geral de produtos do mercado interno brasileiro, vê-se que, desde o século XIX, as transformações já estavam

23 Pouco se fez até hoje para entender a inserção da erva-mate nesse espaço, analisando-a através das ações do INM, tendo mais uma vez que usarmos o que está à disposição e o que foi possível observar até o momento, através de nossa pesquisa em andamento.

24 Há grande dificuldade para estabelecer números precisos de produção e comércio interno, o que "sempre levou os pesquisadores a estimar os totais pelas vendas realizadas, já que os dados referentes a possíveis estocagens do produto inexistem" (Figueiredo, 1967, p. 316), e em alguns casos há preferência por se usar estimativas, que por vezes mostram correspondência com os totais das vendas registrados em alguns boletins estatísticos do INM. Por esses motivos, fazemos ressalvas aos dados que utilizamos neste texto, optando primeiramente pelos dados do instituto, adotando outros quando não houver registros por parte deste. 
ocorrendo, com crescimento populacional e elevação do padrão de vida, especialmente com a libertação dos escravos, que em tese passariam a ser consumidores, e a afluência de imigrantes, que, além de contribuições para o desenvolvimento nacional (embora ao custo da marginalização de alguns grupos, como negros e mestiços, além dos indígenas), se tornaram consumidores especialmente em épocas de altas na economia, como as do café, que fez em alguns momentos abolir "quase inteiramente o sistema de permitir aos trabalhadores das fazendas cultivarem gêneros de consumo (feijão, arroz, milho...)" (Prado Jr., 2004, p. 290, nota 102).

O processo já iniciado de transformações da economia nacional, naquele momento e até a década de 1930, era baseado ainda em grande parte na exportação primária, ou seja, prevalecia o fator produção, mas seriam as mudanças condicionadas "sobretudo pela constituição e ampliação de um mercado interno, isto é, o desenvolvimento do fator consumo, praticamente imponderável no conjunto do sistema anterior" (Prado Jr., 2004, p. 288). Essas mesmas transformações nos ajudam a analisar a situação da erva-mate brasileira, se lembrarmos que, na segunda metade do século XIX, temos a chamada "era de ouro" desse produto, que era vendido nos formatos cancheado (semipreparado) e beneficiado (industrializado), mas em que seu maior impacto se dava com as vendas para os mercados externos, comparado com o reduzido mercado nacional (Costa, 1995, p. 72; Linhares, 1969; Figueiredo, 1967). Antes e durante o período abordado neste texto, ou seja, o tempo de vida do INM, a maior parte desse consumo interno da erva-mate era feita pelo Rio Grande do Sul. Segundo Teodomiro de Souza, em discurso na sessão de instalação do instituto, em 20 de julho de 1938, o consumo brasileiro estava circunscrito praticamente aos gaúchos, com uma média per capita de 5 quilos anuais, "restando aos demais estados a percentagem irrisória, aproximadamente, 200 gramas, enquanto na Argentina e no Uruguai esse consumo atinge de 8 a 9 quilos "per capita"" 25 .

Já nos anos de 1943 e 1944, vemos que o consumo dentro dos quatro estados produtores do Brasil somou em toneladas líquidas de $15.131 \mathrm{e}$ 13.563, respectivamente, e dessa quantia o Rio Grande do Sul ficou

25 Instituto Nacional do Mate, Discurso de Teodomiro L. de Souza, delegado do RS, na sessão de instalação do INM, 20 de julho de 1938. 
com 14.246 toneladas (1943) e 13.012 toneladas (1944), restando ao conjunto dos demais estados (Paraná, Santa Catarina e Território Federal de Ponta Porã $\left.{ }^{26}\right) 884$ toneladas e 551 toneladas, respectivamente ${ }^{27}$.

Já em termos de consumo interno em todos os estados e regiões do país (interestaduais e intraestaduais), produtores ou não, entre $1940 \mathrm{e}$ 1944, temos o seguinte:

Tabela 1 - Consumo interno brasileiro (interestaduais e intraestaduais) - em toneladas

\begin{tabular}{c|c}
\hline ANO & TOTAL \\
\hline 1940 & 16.380 \\
\hline 1941 & 17.553 \\
\hline 1942 & 17.202 \\
\hline 1943 & 18.515 \\
\hline 1944 & 16.255 \\
\hline
\end{tabular}

Fonte: INM (1945, p. 115).

Aqui percebemos que as vendas, nos primeiros anos da década de 1940, se mantiveram estáveis, com média anual de 17.181 toneladas.

Tabela 2 - Consumo interno brasileiro (interestaduais e intraestaduais) - em toneladas

\begin{tabular}{c|c}
\hline ANO & TOTAL \\
\hline 1957 & 30.218 \\
\hline 1958 & 27.645 \\
\hline 1959 & 31.290 \\
\hline 1960 & 38.573 \\
\hline 1961 & 41.098 \\
\hline
\end{tabular}

Fonte: Jordan (5/9/1962).

26 Naquele momento o Território se encontrava separado de Mato Grosso, em razão das políticas adotadas por Getúlio Vargas.

27 Nesses dados só foram consideradas as informações que foram fornecidas através das "Guias de livre-trânsito" do INM, deixando de fora o que não foi declarado até a data do relatório do PINM e, claro, também o que não foi registrado, considerado como contrabando (Instituto Nacional do Mate, Relatório do presidente do Instituto Nacional do Mate, Carlos Gomes de Oliveira, apresentado à Junta Deliberativa, Rio de Janeiro, out. 1945, p. 102). 
Já na Tabela 2 (mais uma vez mostrando a soma das vendas inter e intraestaduais) consta uma quantia anual significativa, que, comparada com os dados da Tabela 1, representa um aumento importante do consumo nacional ${ }^{28}$. Nesse ponto, lembramos ainda outra vez que o mercado de exportação sempre foi o pilar da economia ervateira brasileira, mas com esses números temos uma ideia da proporção que teve o aumento do consumo interno a partir da década de 1950. A média anual do consumo interno já era maior que a média das vendas feitas para a Argentina nesse mesmo período, sendo a média, no caso do consumo brasileiro, de 33.765 toneladas, enquanto para a Argentina a média foi de 21.186toneladas (Jordan, 4/9/1962).

Destacando apenas janeiro-setembro dos anos de 1965 e 1966, o presidente do instituto nos mostra um consumo interno de 25.303 toneladas e 31.943 toneladas, respectivamente. Momento que ele considerava "assaz animador", esperando chegar, até o fim do mesmo ano de 1966, a 40 mil toneladas, e tal fato, "sôbre ser auspicioso, indica que esta percentagem tende a aumentar, posto que no último trimestre do ano as vendas aumentam, seja por se tratar de erva nova ou em consequência de campanhas publicitárias" 29 .

Como temos visto, o instituto tinha como meta a conquista de novos mercados para a erva-mate, mas isso se deu com vistas especialmente para o exterior, aparecendo com foco especial a Europa e os Estados Unidos. No mercado brasileiro, as ações se restringiram a algumas áreas, que incluíam São Paulo e Rio de Janeiro, passando por Minas Gerais, até chegar a alguns estados do Nordeste, como Pernambuco e Bahia. Ainda assim, como pudemos notar nas tabelas que apresentamos, houve de fato um aumento do consumo em nosso país, ainda que em proporção menor que o conjunto dos mercados exteriores. Segundo alguns presidentes do INM, um dos principais entraves para a expansão do mate no mercado brasileiro era o baixo poder aquisitivo da população, sobretudo no Nordeste, que pelo calor se presumiria um bom comprador de

\footnotetext{
28 Aqui não dispomos até o momento de dados do consumo isolado do Rio Grande do Sul nesse período e nem dos demais anos, o que impede uma maior compreensão da evolução do consumo por estado.

29 Instituto Nacional do Mate, Relatório do presidente do Instituto Nacional do Mate, Harry Carlos Wekerlin, apresentado à Junta Deliberativa, Rio de Janeiro, out. 1966, Assuntos Econômicos, p. 6.
} 
mate gelado. Isso explica o fato de focar a maioria de suas ações no Rio de Janeiro e em São Paulo, maiores centros econômicos no período, tendo feito propaganda, inclusive incentivando e promovendo a distribuição gratuita de mate, quente ou gelado, em diversos locais tidos como estratégicos para a conquista dos consumidores cariocas (praias, estádios, grandes empresas, repartições públicas, escolas etc.) e paulistas (como a Casa do Mate, entre outros locais). Nas Casas do Mate, aliás ${ }^{30}$, têm-se um dos experimentos para a propagação no Brasil, que recebeu especial atenção, montadas com melhores ou piores instalações em São Paulo, no Rio de Janeiro, em Recife e em Salvador.

Nesse ponto a questão dos desníveis sociais e econômicos, característica de países como o nosso, afetou, sem dúvida, a ampliação do mercado interno geral e, como visto, da erva-mate de forma direta. Mercado que, no conjunto da economia do país, é deprimido, mesmo tendo em vista que era vital "para o processo de industrialização, ao passo que o recurso à exportação de manufaturados com base num organismo como a Associação Latino-Americana de Livre Comércio (ALALC) tende a repor os mesmos problemas ao nível continental, além de suscitar outros novos" (Cohn, 1978, p. 315).

Finalmente, vale mencionar que foge às estatísticas durante todo período o mate que é produzido e consumido em fazendas, aldeias indígenas - caso especialmente no antigo sul de Mato Grosso - e colônias - no caso da Colônia Agrícola Nacional de Dourados (CAND), também no sul de Mato Grosso, e das colônias onde existia erva-mate no Sul do Brasil -, onde era elemento cultural importante concomitantemente à situação de objeto de comércio (cf. Brand; Ferreira; Almeida, 2015; Ferreira, 2007; Fernandes, 2017; também Eremites de Oliveira; Esselin, 2015).

\section{Os novos mercados}

Além das vendas para os mercados tradicionais (Argentina, Uruguai e Chile), o mate já aparecia em acordos comerciais com os Estados

\footnotetext{
30 Vale notar que os presidentes e diretores do INM nunca chegaram a um consenso em relação à nomenclatura mais adequada, por isso ela aparece ora como Loja, ora como Casa do Mate.
} 
Unidos, desde pelo menos a época do Tratado Comercial de 1935, que foi fundamental para a posição do Brasil na Segunda Guerra Mundial e nos anos seguintes. Naquele momento a erva-mate foi incluída na lista dos seis produtos que teriam suas tarifas rebaixadas (Moura, 1980, p. 79-80 $)^{31}$. No entanto, a média das vendas de erva-mate para os Estados Unidos, entre 1927 e 1932, era de apenas 14 toneladas $^{32}$, tendo mudado muito de 1933 até o ano do tratado, com pico de 107 toneladas exatamente em 1935; depois dele sofreu reduções até chegar a 9 toneladas em 1938, ano de criação do INM ${ }^{33}$. A partir desse ano até 1944, a média das vendas para o mercado norte-americano chegou a 126 toneladas, sendo o pico no ano de 1942, em plena Segunda Guerra, quando o Brasil vendeu a quantia de 623 toneladas $^{34}$. Aliás, a Segunda Guerra deu esperanças aos dirigentes do INM, e o entusiasmo pode então ser notado nos relatórios de seus presidentes daqueles anos (especialmente nos relatórios de Carlos Gomes de Oliveira).

$\mathrm{Na}$ Europa a promoção do mate também foi tentada por parte do instituto, sobretudo depois da guerra.Ações e negociações estiveram em pauta em diversos países, como Alemanha, Inglaterra, Itália e outros, onde o INM se fez presente em exposições internacionais e eventos diversos, investindo em stands, onde o mate era apresentado gelado ou quente no formato de chá ao público. Alguns deles compravam mais que os Estados Unidos, como a Alemanha, o maior entre os novos mercados, que mantinha boas médias: 490 toneladas no período 1927-1932 e 354 toneladas no período 1933-1938 - sofrendo corte a partir de 1940 , motivado pelos conflitos mundiais e pelo consequente rompimento das relações brasileiras com os germânicos, tendo feito a última

31 A lista continha também bálsamo de copaíba, ipecacuanha, minério de manganês, castanhas e mamona. Já se sabe também que a lista incluiu outros produtos que ficariam livres de tarifa: café, cacau, cera de carnaúba, castanhas, óleo de babaçu e madeira (Moura, 1980, p. 80).

32 Instituto Nacional do Mate, Relatório do presidente do Instituto Nacional do Mate, Carlos Gomes de Oliveira, apresentado à Junta Deliberativa, Rio de Janeiro, out. 1945, p. 111.

33 Ainda assim, sendo a média anual de 65toneladas no período de 1935-1938 (Instituto Nacional do Mate, Relatório do presidente do Instituto Nacional do Mate, Carlos Gomes de Oliveira, apresentado à Junta Deliberativa, Rio de Janeiro, out. 1945, p. 112).

34 Instituto Nacional do Mate, Relatório do presidente do Instituto Nacional do Mate, Carlos Gomes de Oliveira, apresentado à Junta Deliberativa, Rio de Janeiro, out. 1945, p. 113. 
venda em 1939, na quantia de 114 toneladas $^{35}$. Como em relação aos Estados Unidos, as negociações com os países europeus, incluindo a Alemanha Ocidental do pós-guerra, acabaram não rendendo o esperado, apesar de constantes manifestações de entusiasmo por parte dos representantes, agentes e presidentes do INM.

Fora da Europa, em menor quantidade e irregularmente, o mate também rumou para países do Oriente Médio (como Síria, Líbano, Israel, entre outros), constando em estatísticas as remessas do produto, às vezes não especificando o país separadamente na documentação, incluídos apenas como "outros destinos", oscilando bastante em quantidade, mas nunca muito expressivamente - com pico no conjunto de 292 toneladas em $1940^{36}$ e especificamente para a Síria, na quantia de 160 toneladas em 1964 (Figueiredo, 1967, p. 336b).

Nesses novos mercados que se pretendeu conquistar, alguns capitalistas demonstraram interesse por investir na produção de erva-mate dentro de seus países, mas os obstáculos foram quase sempre intransponíveis - como barreiras impostas por governos e desacordos nas negociações entre os interessados. Era o caso da Inglaterra, que, segundo o presidente do INM, demonstrava "desusado interesse", manifestado por pequenas encomendas e pela aproximação do instituto com "firmas de importância" que desejavam comprar erva-mate, mas que, em meados da década de 1940, tinham o sério embaraço imposto pelo governo inglês, que "limitava ali as licenças de importação a 30 toneladas apenas, anualmente" 37 . Em relação a isso, o INM buscou o Ministério das Relações Exteriores, que, através de um acordo que incluiu o mate, conseguiu a revogação da medida limitadora, abrindo a possibilidade de concretizar um acordo preliminarmente estabelecido pelo INM com a firma Hugo C. Braun, de Londres, que se dizia interessada em colocar um mínimo de 500 toneladas anuais, "mantendo o serviço de propaganda na Inglaterra por sua conta e responsabilidade" 38 , e esperava também, segundo o presi-

35 Instituto Nacional do Mate, Relatório do presidente do Instituto Nacional do Mate, Carlos Gomes de Oliveira, apresentado à Junta Deliberativa, Rio de Janeiro, out. 1945, p. 111-113.

36 Instituto Nacional do Mate, Relatório do presidente do Instituto Nacional do Mate, Carlos Gomes de Oliveira, apresentado à Junta Deliberativa, Rio de Janeiro, out. 1945, p. 113.

37 Instituto Nacional do Mate, Relatório do presidente do Instituto Nacional do Mate, Generoso Ponce Filho, apresentado à Junta Deliberativa, Rio de Janeiro, out. 1946, p. 48.

38 Instituto Nacional do Mate, Relatório do presidente do Instituto Nacional do Mate, Generoso Ponce Filho, apresentado à Junta Deliberativa, Rio de Janeiro, out. 1946, p. 49. 
dente do instituto, aplicar igual critério para os mercados da Itália, Espanha, Suécia, França, Bélgica, Suíça e de Portugal. Mas, ainda em relação ao mercado inglês, basta uma observação nas exportações dos anos subsequentes, para perceber que as coisas não ocorreram como o esperado, sendo a média de vendas para esse mercado entre 1959 e 1965 de pouco mais de 30 toneladas (Figueiredo, 1967, p. 330a). Parte considerável do insucesso se deve à falta de recursos do INM para industrializar o mate de acordo com o paladar europeu, que não via com bons olhos o consumo de chimarrão e formatos semelhantes.

Em outros casos, que envolviam jogos de interesse, os brasileiros queriam fornecer o mate já industrializado, o que impedia o atendimento de algumas exigências por parte dos investidores, desejosos de comprar matéria-prima, ou seja, cancheada ou derivados de mate. A aceitação do fornecimento de cancheada seria, segundo Costa (1995), fundamental para manter o mercado ervateiro, o que não foi aceito naquele momento pelos industriais e exportadores brasileiros e por isso teria levado a erva-mate ao colapso das exportações para a Argentina, na década de 1960. Ainda sobre essa última situação, com exceção do que já ocorria com o beneficiamento do mate que seguia cancheado para a Argentina ${ }^{39}$ e em parte para o Uruguai ${ }^{40}$, não há notícias de que esses empreendimentos tenham dado resultado no exterior, nos novos mercados que se pretendia conquistar, especialmente na maior potência capitalista do século XX, os Estados Unidos. Mas, caso isso ocorresse, poderíamos ter uma imagem do que nos fala Caio Prado Jr. a respeito da industrialização brasileira e da sua submissão ao imperialismo, que deteria a possível tecnologia avançada de beneficiamento do mate, restando ao Brasil exportar matéria-prima, sendo a parcela maior dos lucros retida pelas empresas estrangeiras (Prado Jr., 2004, p. 328). Claro que caberá em momento futuro analisar a quem interessaria no caso brasileiro tal situação e que grupos ganhariam com o fornecimento de cancheada para os novos mercados, nos moldes imperialistas.

39 Só para citarmos o caso de Mato Grosso, a Companhia Mate Laranjeira exportava o mate para uma beneficiadora própria existente na Argentina, isso desde o século XIX até pelo menos a década de 1940 .

40 Nesse caso teríamos as indústrias uruguaias, que foram surgindo, sobretudo, a partir da década de 1940. 


\section{Considerações finais}

Em termos de considerações finais, podemos a princípio dizer que existem muitas lacunas, quando se fala em economia ervateira, sobretudo no que se refere à trajetória, às ações do Instituto Nacional do Mate e aos efeitos delas. O trabalho ainda comporta uma série ampla de pesquisas, que inclui revisões e debates com autores que já trataram, ao menos indiretamente, sobre o INM.Vimos em nosso panorama que o cenário econômico nacional afetou suas ações, resultando na sua criação e, com as mudanças advindas do golpe de 1964, na sua extinção. Situação que pode ser percebida nas atas das reuniões da Junta Deliberativa e da Diretoria, no que diz respeito à propaganda, aos cortes de gastos, às reduções do quadro de funcionários, às substituições e reorganizações de estatutos. Além disso, questionamentos à sua validade e às ameaças de fechamento do INM por parte do Governo Federal existiram desde a década de $1940^{41}$.

Sendo assim, ainda há muito que se pensar em como inserir a erva-mate nas condições e transformações da economia nacional, no período 1938-1967, no que envolverá maior atenção ao processo de industrialização do produto, à ampliação do mercado interno brasileiro e às medidas adotadas (com ou sem êxito) para a conquista de novos mercados exteriores. E, nesse último caso, produto de exportação, procurando se estabelecer no mercado norte-americano, buscando substituir os tradicionais compradores, nos faz questionar o que há de subsunção (se há) e o que há de submissão mais ou menos direta ao imperialismo dos EUA e países europeus capitalistas do pós-Segunda Guerra - em resumo, a perpetuação da velha condição brasileira.

41 Nesse caso, especialmente no governo Dutra, quando do projeto de criação do Banco Central se cogitou a extinção do INM (Relatório do presidente do Instituto Nacional do Mate, Generoso Ponce Filho, apresentado à Junta Deliberativa, Rio de Janeiro, out. 1947, p. 1-3). Mas, mesmo nos anos finais do governo constitucional de Vargas, já se tinha em mente a permanência ou não da autarquia, pois, segundo o mesmo presidente do INM, foi através da Conferência Econômica de Teresópolis (1 a 6 de maio de 1945) que se decidiu manter a existência do INM (Relatório do presidente do Instituto Nacional do Mate, Generoso Ponce Filho, apresentado à Junta Deliberativa, Rio de Janeiro, out. 1948, p. 2). 


\section{Referências bibliográficas}

BRAND,Antonio J.; FERREIRA, Eva M.L.;ALMEIDA, Fernando A.A. de. Os Kaiowá e Guarani em tempos da Cia Matte Larangeira: negociações e conflitos. ANAIS DO XXIII SIMPÓSIO NACIONAL DE HISTÓRIA - HISTÓRIA, GUERRA E PAZ. Londrina:ANPUH, 2015, CD-ROM. Disponível em <http://anpuh.org/ anais/wp-content/uploads/mp/pdf/ANPUH.S23.0129.pdf>. Acesso em 29/1/2015.

COHN, Gabriel. Problemas de industrialização no século XX. In: MOTA, Carlos Guilherme. Brasil em perspectiva. 10. ed. Rio de Janeiro/São Paulo: DIFEL, 1978.

COSTA, Samuel Guimarães da. A erva-mate. Curitiba: Farol do Saber, 1995 (Coleção Farol do Saber).

EREMITES DE OLIVEIRA, Jorge; ESSELIN, Paulo Marcos. Uma breve história (indígena) da erva-mate na região platina: da Província do Guairá ao antigo sul de Mato Grosso. Espaço Ameríndio. Porto Alegre, v. 9, n. 3, p. 278-318, jul.-dez. 2015.

FERNANDES, José A. Erva mate e frentes pioneiras: dois mundos em um só espaço (1945 a 1970). Curitiba: Prismas, 2017.

FERREIRA, Eva Maria Luiz. A participação dos índios Kaiowá e guarani como trabalhadores nos ervais da companhia Matte Larangeira (1902-1952). Dourados: UFGD, 2007 (Dissertação de Mestrado em História).

FIGUEIREDO, Alvanir de. A presença geoeconômica da atividade ervateira: com destaque da zona ervateira do estado de Mato Grosso, tomada como referência. Presidente Prudente: Faculdade de Filosofia, Ciências e Letras, 1967 (Tese de Doutorado em Geografia).

FURTADO, Celso. Brasil: tempos modernos. Rio de Janeiro: Paz e Terra, 1968.

FURTADO, Celso. Formação econômica do Brasil.34. ed. 7. impr. São Paulo: Cia. das Letras, 2007.

GERHARDT, Marcos. História ambiental da erva-mate. Florianópolis: UFSC, 2013 (Tese de Doutorado em História).

IBDF - Instituto Brasileiro de Desenvolvimento Florestal. Erva-mate: origem, cultura e industrialização. Departamento de Industrialização e Comercialização, Ministério da Agricultura, 1975.

INM - Instituto Nacional do Mate. Relatório do presidente do Instituto Nacional do Mate, Carlos Gomes de Oliveira, apresentado à Junta Deliberativa. Rio de Janeiro, out. 1945.

IPEA - Instituto de Pesquisa Econômica Aplicada. A controvérsia do planejamento na economia brasileira - coletânea da polêmica Simonsen x Gudin, desencadeada com as primeiras propostas formais de planejamento da economia brasileira ao final do Estado Novo - Roberto Cochrane Simonsen, Eugenio Gudin. 3. ed. Brasília: IPEA, 2010.

JORDAN, Felinto. A erva-mate na indústria catarinense. A Notícia, 4 e 5/9/1962.

LINHARES, Temístocles. História econômica do mate. Rio de Janeiro:José Olympio, 1969. 
MOURA, Gerson. Autonomia na dependência: a política externa brasileira de 1935 a 1942. Rio de Janeiro: Nova Fronteira, 1980.

OLIVEIRA, Marisa C. de. Estudo da erva mate no Paraná, 1939-1967. Curitiba: Universidade Federal do Paraná, 1974 (Dissertação de Mestrado em História).

PRADO JR., Caio. A revolução brasileira. 7. ed. São Paulo: Brasiliense, 1987.

PRADO JR., Caio. História econômica do Brasil. 46. impr. São Paulo: Brasiliense, 2004.

RECKZIEGEL, Ana Luiza Sett. A integraçãoeconômica entre Brasil e Argentina (1951-54). Possibilidades e limites, 2005. Disponível em Rede Tchê <http://cdn.fee.tche.br/ jornadas/2/H2-02.pdf>. Acesso em 25/7/2016.

ROSA, Lilian da. A trajetória do setor ervateiro na Província do Rio Grande do Sul. Campinas: UNICAMP, 2015 (Dissertação de Mestrado em Desenvolvimento Econômico).

ZARTH, Paulo Afonso. História agrária do planalto gaúcho, 1850-1920. Ijuí: UNIJUÍ, 1997. 